\title{
New Developments in the Treatment of Acute Myocardial Infarction Associated with Out- of-Hospital Cardiac Arrest. A Review
}

\author{
Monica Marton-Popovici ${ }^{1}$, Dietmar Glogar ${ }^{2}$ \\ ${ }^{1}$ Swedish Medical Center, Department of Internal Medicine and Critical Care, Edmonds, Washington, USA \\ ${ }^{2}$ Medical University of Vienna, Austria
}

\begin{abstract}
Out-of-hospital cardiac arrest (OHCA) occurring as the first manifestation of an acute myocardial infarction is associated with very high mortality rates. As in comatose patients the etiology of cardiac arrest may be unclear, especially in cases without ST-segment elevation on the surface electrocardiogram, the decision to perform or not to perform urgent coronary angiography can have a significant impact on the prognosis of these patients. This review summarises the current knowledge and recommendations for treating patients with acute myocardial infarction presenting with OHCA. New therapeutic measures for the post-resuscitation phase are presented, such as hypothermia or extracardiac life support, together with strategies aiming to restore the coronary flow in the resuscitation phase using intra-arrest percutaneous revascularization performed during resuscitation. The role of regional networks in providing rapid access to the hospital facilities and to a catheterization laboratory for these critical cardiovascular emergencies is described.
\end{abstract}

Keywords: out-of-hospital cardiac arrest, cardiopulmonary resuscitation, life support, intra-arrest PCI

\section{ARTICLE HISTORY}

Received: 16 September, 2016

Accepted: 10 November, 2016

\section{CORRESPONDENCE}

Monica Marton-Popovici

Swedish Medical Center

Department of Internal Medicine and

Critical Care

21601, 76 ${ }^{\text {th }}$ Ave W, Edmonds,

Washington, 98026, USA

E-mail: monica.marton-popovici@

swedish.org

\section{INTRODUCTION}

Out-of-hospital cardiac arrest (OHCA) occurring as the first manifestation of an acute myocardial infarction (AMI) is associated with very high mortality rates. When cardiac arrest occurs out-of-hospital, delays in the initiation of resuscitation can lead to a poorer prognosis and a significant neurological deficit, even in the eventuality of a successful resuscitation. As in many circumstances the etiology of cardiac arrest remains unclear in comatose patients, especially in those cases without STsegment elevation on the surface electrocardiogram, the decision to perform or not to perform urgent coronary angiography can have a crucial impact on the prognosis of these patients. New therapeutic measures such as hypothermia and extracardiac life support have been proposed to improve survival rates in these critical cardiac emergencies. Intra-arrest percutaneous coronary intervention (PCI) has also been attempted in the hope that urgent revascularization of the occluded coronary artery may lead to the immediate restoration of myocardial contractility and recovery of the circulation (Figure 1). This review summarizes current knowledge and recom- 


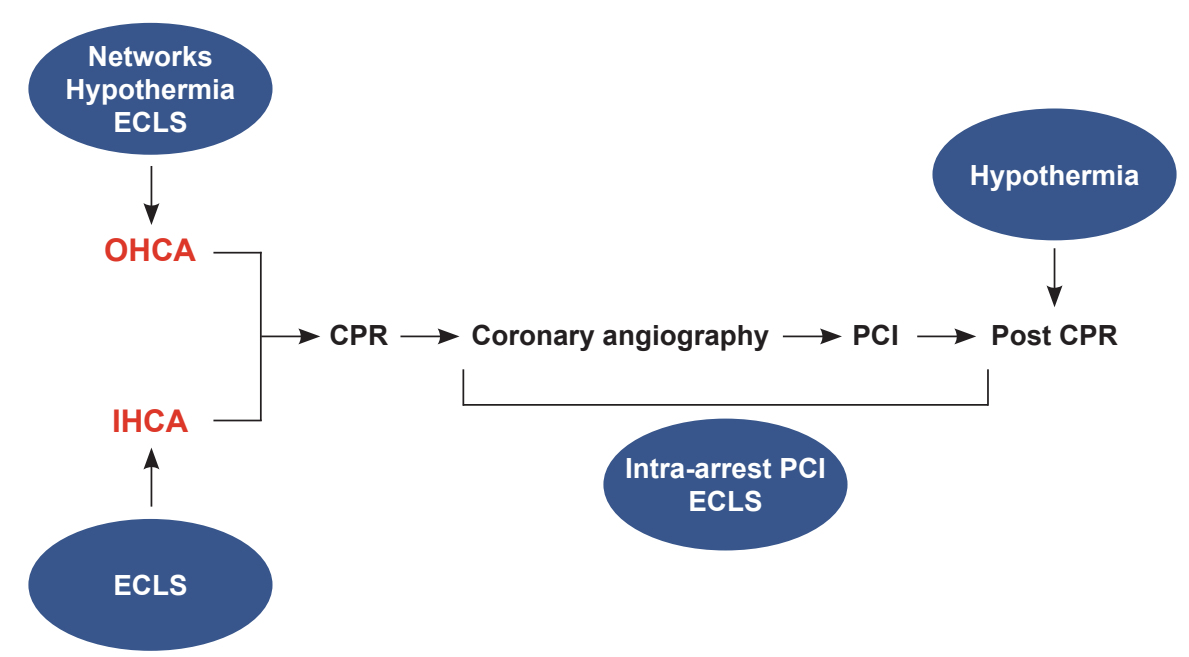

FIGURE 1. Modern approaches in cardiac arrest with suspected ischemic etiology.

OHCA - out-of-hospital cardiac arrest, IHCA - in-hospital cardiac arrest, ECLS - extra-corporeal life support, CPR - cardiopulmonary resuscitation, $\mathrm{PCI}$ - percutaneous coronary intervention

mendations for treating patients with AMI presenting with OHCA.

\section{OUT-OF-HOSPITAL CARDIAC ARREST - A MAJOR HEALTHCARE PROBLEM}

Out-of-hospital cardiac arrest (OHCA) is defined as an unexpected sudden onset condition with the absence of palpable central pulse and apnea, attributed to mechanical cardiac inactivity. Although the incidence and survival rates associated with this condition vary considerably in different regions of the world, it remains one of the leading causes of death and invalidity in industrialized countries, with a summary incidence of 38 per 100,000 person-years for all-rhythm OHCA in Europe., The main etiologies of OHCA are represented by different cardiovascular conditions, mainly attributed to ischemic heart diseases complicated by an acute coronary syndrome (ACS) or a stroke. ${ }^{3}$ However, it was reported that between $20 \%$ and $40 \%$ of OHCA in adult patients were of non-cardiac origin, indicating that further investigations are needed to identify other risk factors involved in OHCA etiology. ${ }^{4}$ Survival rates of OHCA patients also show considerable variability for different countries and regions depending on the standard of medical education about cardiopulmonary resuscitation (CPR), on the development of emergency medical services (EMS) and on public access to external defibrillators. ${ }^{5}$ In developing countries, the incidence of cardiovascular diseases and OHCA is higher than in industrialized countries. The lack of standardized emergency medical systems and poor public awareness predisposes to mortality rates as high as $98-100 \%$ in these regions. ${ }^{6}$ In one study it was suggested that the survival rate of OHCA patients might be age- and sex-related, with a higher overall rate of survival in women, with differences across age groups, indicating that women younger than forty-seven years had a higher probability of survival after an OHCA. ${ }^{7}$

\section{OUT-OF-HOSPITAL CARDIAC ARREST ASSOCIATED WITH ACUTE MYOCARDIAL INFARCTION}

Despite the progress made in the last decades in the prevention of coronary artery diseases (CAD) and improved treatment strategies with either optimal medical therapy or percutaneous coronary interventions (PCI) for ischemic heart diseases, the mortality associated with acute myocardial infarction (AMI) is still high. ${ }^{8-10}$ A substantial number of sudden cardiac arrests related to AMI occur outside the hospital, and this is associated with higher mortality rates compared to patients with in-hospital cardiac arrest (IHCA). This is mainly attributed to the late initiation of CPR and advanced life support therapies in out-of-hospital settings. ${ }^{11}$ A significant number of OHCA survivors have a low quality of life due to significant neurological sequelae secondary to cerebral hypoxia. ${ }^{12}$ Ostenfeld et al. (2015) evaluated mortality in patients with AMI complicated by cardiogenic shock (CS) presenting with or without OHCA and found no significant differences in survival rates between the two groups, suggesting that OHCA 
cannot be considered as an independent predictor of mortality in the severe group of AMI patients with CS. ${ }^{13}$

\section{MANAGEMENT OF PATIENTS SURVIVING OHCA}

\section{RECOMMENDATIONS FOR REVASCULARIZATION IN OHCA ASSOCIATED WITH AMI}

As multiple non-randomized trials suggest that OHCA survivors can benefit from immediate coronary angiography and PCI, with improved survival rates following revascularization procedures, the guidelines of the European Society of Cardiology (ESC) recommend emergency coronary angiography with revascularization in patients with AMI and OHCA, regardless of ECG findings, as a class IIa indication. According to ESC guidelines, conscious patients surviving OHCA with ST-segment elevation myocardial infarction (STEMI) should be treated immediately with PCI, while high-risk non-ST-segment elevation acute coronary syndrome should receive rapid invasive therapy in less than two hours. ${ }^{1 / 4}$ Unconscious patients should be transferred immediately to the catheterization laboratory. ${ }^{15}$ The guidelines of the American Heart Association (AHA) recommend emergency coronary angiography and PCI for the management of OHCA patients if the ECG shows STEMI (Class I, level of evidence B) and emergency angiography of comatose patients regardless of ST-segment elevation on the ECG (Class IIa, level of evidence B) ${ }^{16}$

\section{CORONARY ANGIOGRAPHY AND REVASCULARIZATION IN OHCA PATIENTS}

The majority of OHCA events associated with AMI result from erosion or rupture of an atherosclerotic coronary plaque ${ }^{17}$ and numerous studies suggest that to decrease mortality, conventional immediate angiography and revascularization should be performed for survivors of OHCA, regardless of ECG changes and symptoms. ${ }^{18}$ Waldo et al. (2015) proposed a straightforward and easily measurable score based on four risk variables in resuscitated patients, including angina, congestive heart failure, the presence of a shockable rhythm on an electrocardiogram as the initial rhythm, and ST-segment elevation in at least two contiguous leads. Patients with a risk score $\leq 1$ are considered as a slight risk of having an acute culprit lesion. Thus, they should not be referred for immediate coronary angiography. A risk score $>1$ is associated with a high likelihood of having an acute coronary lesion, and these patients may benefit from invasive coronary angi- ography. However, further prospective studies are needed to validate this clinical risk model. ${ }^{19}$

The importance of early coronary angiography for cardiac arrest survivors is augmented by recently published results. Kern et al. (2011) demonstrated better outcomes regarding survival and neurological function for patients receiving immediate coronary angiography, regardless of ST-segment changes. A recent study on OHCA patients undergoing urgent catheterization indicated that coronary angiography revealed an acute coronary occlusion in one out of four patients with OHCA without STEMI.

Patients with ST-segment elevation or left bundle branch block (LBBB) with the return of spontaneous circulation (ROSC) following resuscitation, are also likely to benefit from early invasive management and should be referred immediately to the catheterization laboratory. Observational studies demonstrated better outcomes, with reduction of in-hospital mortality and higher rate of a favourable neurological status, when early PCI was associated with targeted temperature management. ${ }^{22-25}$

In patients without ST-segment elevation, as recorded on the post-ROSC electrocardiogram, the decision to perform early PCI can depend on numerous factors. ${ }^{26}$ As the specificity and sensitivity of clinical data and biomarkers are less accurate after OHCA, a decision may be extremely difficult to arrive at in such cases. Hemodynamic status, age, duration of CPR or neurological status can all influence the decision of undertaking or postponing coronary angiography. The current consensus released by the European Association for Percutaneous Cardiovascular Interventions (EAPCI) stated that where there is of lack of an apparent non-coronary cause of OHCA, coronary angiography should be performed in less than two hours. ${ }^{24,25,27}$

A recent study that included 407,974 patients with OHCA presenting with ventricular tachycardia or ventricular fibrillation as initial rhythm, discussed the current trends, outcomes and predictors of performing coronary angiography and PCI in this group. Coronary angiography was performed in only $35 \%$ of patients, increasing from $27.2 \%$ in 2000 to $43.9 \%$ in 2012 , while the PCI rate increased from $9.5 \%$ to $24.1 \%$ during this period. The overall survival-to-discharge rate increased from $46.9 \%$ to $60.1 \%$ ( $p<0.001$ for trend) in the overall study population, with an increase from $59.2 \%$ to $74.3 \%$ ( $\mathrm{p}<0.001$ for trend) in patients with STEMI and from $43.3 \%$ to $56.8 \%$ in those without ST-segment elevation. The study concluded that even if survival-to-discharge rates have increased, a significant number of OHCA patients are still not investigated using coronary angiography. ${ }^{28}$

Geri et al. (2015) analyzed the short- and long-term mortality of patients who underwent immediate coronary 
angiography and PCI after OHCA. In this study 1,722 patients were included, 628 (35.6\%) receiving coronary angiography, $615(35.7 \%)$ receiving coronary angiography without PCI and $479(27.8 \%)$ receiving PCI. Thirty-day survival rates were $21 \%, 11.9 \%$ and $35 \%$ respectively and the ten-year survival rates were $29 \%, 43 \%$ and $38 \%$ respectively in this patient population. Patients with immediate PCI after OHCA presented a significantly lower risk of mortality in the long-term. This study demonstrated that PCI should be carried out in all OHCA survival patients with no obvious non-cardiac cause for the cardiac arrest. ${ }^{29,30}$

Another study which analyzed the short- and longterm outcomes of emergency coronary angiography after OHCA in comatose patients with STEMI or non-STEMI, revealed that age, time to ROSC and the presence of comorbidities were independent predictors of thirty-day and one-year mortality in STEMI patients, while no clinical benefit of immediate coronary angiography/PCI was identified in patients without STEMI. ${ }^{31}$

\section{INTRA-ARREST PCI — A VALID CONCEPT?}

Even though early revascularization therapy is recommended for cardiac arrest survivors, only a few studies addressed the role and clinical benefits of intra-arrest PCI. ${ }^{32}$ In an observational study Kagawa et al. (2012) included 86 patients with ACS unresponsive to conventional CPR. Intra-arrest PCI combined with rapid-response extracorporeal membrane oxygenation (ECMO) was performed for 61 patients $(71 \%)$, leading to return of spontaneous heartbeat in all cases. Mild hypothermia was induced in thirty-two patients $(37 \%)$ in this study. In patients who survived up to thirty days, the rate of OHCA was lower ( $28 \%$ vs. $58 \%$; $p=0.01$ ), the time interval from the arrest to the initiation of extracorporeal life support was shorter (40 minutes vs. 54 minutes; $\mathrm{p}=0.002$ ) and the rate of intra-arrest PCI was higher $(88 \%$ vs. $70 \%$; $=0.04)$. At the same time, the thirty-day survival rate was greater in patients with intra-arrest PCI ( $36 \%$ vs. $12 \% ; \mathrm{p}=0.03$ ). The study concluded that intra-arrest PCI combined with extracorporeal life support was associated with better survival rates for patients with refractory cardiac arrest, demonstrating that intra-arrest PCI is a valid concept that requires further development. ${ }^{33}$

\section{POST-RESUSCITATION CARE - THERAPEUTIC HYPOTHERMIA AFTER OHCA}

Induced mild hypothermia after global cerebral hypoxia is associated with improved outcomes as a consequence of the neuroprotective effect, via suppressing different path- ways of cell death, decreasing cerebral oxygen consumption and reducing the release of stimulatory amino acids and free radicals. ${ }^{34-37}$

Over the last decade, therapeutic hypothermia has become standard care for comatose patients after OHCA with a shockable rhythm, but an analysis of the current studies on therapeutic hypothermia in patients with non-shockable rhythm indicates that controversy still exists.

A large cohort study compared mild induced therapeutic hypothermia at $32-34^{\circ} \mathrm{C}$ for 24 hours, followed by passive $0.3^{\circ} \mathrm{C}$ per hour rewarming to $37^{\circ} \mathrm{C}$ in 24 hours with no temperature management in patients after OHCA. This study demonstrated a better neurologic outcome at discharge for patients with initial VT/VF rhythm compared to those in pulseless electrical activity (PEA)/asystole (39\% vs. $16 \%$; p <0.001). ${ }^{38,39}$ Testori et al. (2011) investigated the outcomes of patients with non-shockable initial rhythm after OHCA treated with mild induced therapeutic hypothermia for 24 hours, and demonstrated improved neurological outcome at discharge, associated with a reduced risk of mortality. ${ }^{40,41}$ The FINNRESUSCI study (2013) also reported improved neurological status at one-year followup in patients with shockable rhythm after OHCA with therapeutic hypothermia, but no benefit was observed for patients with non-shockable rhythm..$^{42}$

In the Targeted temperature management (TTM) trial (2013), 950 unconscious OHCA patients were randomly assigned to TTM at either $33^{\circ} \mathrm{C}$ or $36^{\circ} \mathrm{C}$, achieved as rapidly as possible with ice-cold fluids and ice packs. After twenty-eight hours re-warming to $37^{\circ} \mathrm{C}$ was performed in both groups. No significant differences were observed in the primary outcome of all-cause mortality at the end of the trial between the two groups. The six-month neurological outcome was also similar in the two groups. ${ }^{43,44}$

An extensive retrospective registry study, which compared the effectiveness of therapeutic hypothermia after OHCA, found no significant neurological benefit at discharge compared to no temperature management, reporting worse neurological outcome in patients with nonshockable rhythm. ${ }^{45,46}$

The optimal duration of TTM is yet unknown, but currently, most recommendations indicate that this therapy should be maintained for at least twenty-four hours. No differences were observed in mortality and neurological outcomes with twenty-four-hour versus seventytwo-hour hypothermia. Current European Resuscitation Council and European Society of Intensive Care Medicine guidelines recommend that a target temperature between $32-36^{\circ} \mathrm{C}$ should be achieved if TTM is used after OHCA. According to these guidelines, TTM is recommended after 
OHCA for patients with shockable rhythm on initial ECG, who are unresponsive after ROSC, and for those with initial non-shockable rhythm on the ECG who remain unresponsive after ROSC. According to current recommendations, TTM should be maintained for at least twenty-four hours. ${ }^{47}$ ESC and AHA guidelines also recommend (Class I indication) the use of TTM for STEMI patients who are resuscitated after cardiac arrest but remain comatose at arrival at a hospital. 48,49

The duration of coma in OHCA survivors is related to various factors, such as the duration of cardiopulmonary resuscitation, initial rhythm, arrest location, witnessed arrest, and sex. In an observational study on 573 patients with OHCA treated with TTM, 316 patients (55\%) became responsive, 60 (19\%) woke up at least 48 hours after rewarming and 8 patients (2.5\%) woke up more than one week after re-warming. This study also observed a better neurological status at discharge in early awakeners..$^{50}$

As the use of TTM becomes more frequent in clinical practice, safety issues arise in relation to this new strategy. Bleeding, infectious and arrhythmic complications have been reported. TTM can alter the coagulation cascade, and dual antiplatelet therapy combined with potent antithrombotic agents can increase bleeding risk for patients undergoing PCI. A meta-analysis of five studies reported no significant increase in bleeding complications or blood transfusion for patients with TTM treatment..$^{51}$ Joffre et al. (2014) reported a higher rate of stent thrombosis in comatose patients with OHCA treated with TTM and PCI. This could be explained by the pharmacokinetic changes following hypothermia, the higher rate of nonresponders to clopidogrel, the presence of circulatory shock or insufficient antiplatelet therapy. ${ }^{52}$ Another study, which evaluated the incidence of stent thrombosis in 49,109 patients treated with TTM and PCI for AMI after cardiac arrest, concluded that the rate of stent thrombosis was not significantly different in patients who received TTM compared to those on standard care. ${ }^{53,54}$

In a systematic review on therapeutic hypothermia after cardiac arrest, it was reported that excellent survival rates with clear neuroprotective benefit followed the use of therapeutic hypothermia (TH), regardless of initial rhythm after survival of OHCA. However, this study did not demonstrate any evidence in favour of a specific temperature. 55,56

The timing of initiation of $\mathrm{TH}$ is still a topic of debate. Some authors suggest that early initiation of TTM, with prehospital initiation, could be beneficial for OHCA patients, preventing profound brain injury and limiting early reperfusion injury. As yet no clinical benefit has been proven for this approach, which was also associated with longer times from therapy initiation to hospital arrival. ${ }^{57-59}$

\section{POST-RESUSCITATION SUPPORTIVE THERAPY IN OHCA PATIENTS}

Extracorporeal life support (ECLS) is a secondary therapy to conventional $\mathrm{CPR}$, which is associated with improved survival and neurological outcomes. It is mainly used if there is a suspected reversible etiology related to the cardiac arrest. ECLS can be initiated at the site where OHCA occurred. However, the results were significantly worse in OHCA than in-hospital cardiac arrest (IHCA).$^{60-63} \mathrm{~A}$ recent meta-analysis on the efficacy of extracorporeal cardiopulmonary resuscitation compared to conventional CPR revealed no differences in survival rates and neurologic outcomes in OHCA patients, despite this therapy leading to improved survival and better neurologic outcome in IHCA of cardiac origin. ${ }^{64}$

Another approach, which raises serious ethical questions, is the use of extracorporeal membrane oxygenation (ECMO) to preserve organs for transplantation from refractory OHCA patients. ${ }^{65}$ Dalle et al. (2016) suggested that ECMO should be used for ECPR, as well as for uncontrolled donation after circulatory determination of death for organ transplanteligible patients. However, only top centers in ECLS should develop this kind of protocol, and ECLS should always be considered before the initiation of these protocols. ${ }^{66,67}$

\section{NETWORK DEVELOPMENT FOR REDUCTION OF MORTALITY}

The most frequent underlying cause of OHCA is the presence of an ACS, and emergency PCI may be associated with improved survival in these cases. ${ }^{23,68}$ The development of well-organized STEMI networks has led to a significant reduction of in-hospital mortality in STEMI patients, and OHCA patients may also benefit from these networks. ${ }^{69-71}$ The development of highly specialized centers for cardiac arrest, with well-trained staff and state-of-the-art equipment, capable of primary PCI and advanced post-resuscitation care, can also have a role in reducing mortality and achieving better neurological outcomes. ${ }^{72-76}$ A system-wide approach for early CPR in the community could also achieve decreased death rates for OHCA patients and improve neurological outcomes. ${ }^{77-79}$ The implementation and development of OHCA registries may lead to a better understanding of these complex conditions and help identify the needs for targeted interventions in regional networks. ${ }^{80,81}$ 


\section{CONCLUSIONS}

Acute myocardial infarction associated with cardiac arrest remains a major healthcare problem, and OHCA occurring at the onset of infarction requires prompt intervention to identify the ischemic cardiac etiology of the cardiac arrest accurately and to initiate appropriate reperfusion strategy. Urgent coronary angiography should be performed in all cases with suspected ischemic etiology and in all cases with unknown etiology of the cardiac arrest, as revascularization of the culprit lesion has been demonstrated to improve the survival in these patients. Complex therapeutic strategies have been proposed to reduce the mortality associated with this condition. However, few strategies have been linked with a significant decrease in mortality. The implementation of modern approaches in the therapeutic algorithm dedicated to OHCA still requires significant efforts and the organization of efficient regional networks for acute cardiac care.

\section{CONFLICT OF INTEREST}

Nothing to declare.

\section{REFERENCES}

1. Go AS, Mozaffarian D, Roger VL, et al. Heart Disease and Stroke Statistics-2014 Update. Circulation. 2014;129:e28-e292. https://doi.org/10.1161/01.cir.0000441139.02102.80

2. Berdowski J, Berg RA, Tijssen JG, Koster RW. Global incidences of out-of-hospital cardiac arrest and survival rates: Systematic review of 67 prospective studies. Resuscitation. 2010;81:14791487. doi: 10.1016/j.resuscitation.2010.08.006.

3. Fukuda T, Ohashi-Fukuda N, Kondo Y, Sera T, Doi K, Yahagi N. Epidemiology, Risk Factors, and Outcomes of Out-ofHospital Cardiac Arrest Caused by Stroke: A Population-Based Study. Medicine (Baltimore). 2016;95:e3107. doi: 10.1097/ MD.0000000000003107.

4. Kitamura T, Kiyohara K, Sakai T, et al. Epidemiology and outcome of adult out-of-hospital cardiac arrest of noncardiac origin in Osaka: a population-based study. BMJ Open. 2014;4:e006462. doi:10.1136/bmjopen-2014-006462.

5. Hawkes C, Booth S, Ji C, et al. Epidemiology and outcomes from out-of-hospital cardiac arrests in England. Resuscitation. 2017;110:133-140. doi: 10.1016/j.resuscitation.2016.10.030.

6. Mawani M, Kadir MM, Azam I, et al. Epidemiology and outcomes of out-of-hospital cardiac arrest in a developing country-a multicenter cohort study. BMC Emergency Medicine. 2016;16:1. doi: 10.1186/s12873-016-0093-2.

7. Safdar B, Stolz U, Stiell IG. Differential survival for men and women from out-of-hospital cardiac arrest varies by age: results from the OPALS study. Acad Emerg Med. 2014;21:15031511. doi: 10.1111/acem.12540.

8. Chen HY, Gore JM, Lapane KL, et al. A 35-Year Perspective (1975 to 2009) into the Long-Term Prognosis and Hospital Management of Patients Discharged from the Hospital After a
First Acute Myocardial Infarction. Am J Cardiol. 2015;116:2429. doi: 10.1016/j.amjcard.2015.03.035.

9. Nichols M, Townsend N, Scarborough P, Rayner M.Cardiovascular disease in Europe 2014: epidemiological update. Eur Heart J. 2014;35:2950-2959. doi: 10.1093/ eurheartj/ehu299.

10. Goraya TY, Jacobsen SJ, Kottke TE, Frye RL, Weston SA, Roger VL. Coronary heart disease death and sudden cardiac deaths: a 20- year population-based study. Am J Epidemiol. 2003;157:763-770.

11. Aso S, Imamura $\mathrm{H}$, Sekiguchi $\mathrm{Y}$, et al. Incidence and mortality of acute myocardial infarction. A population-based study including patients with out-of-hospital cardiac arrest. Int Heart J. 2011;52:197-202.

12. Noc M, Fajadet J, Lassen JF, et al. Invasive coronary treatment strategies for out-of-hospital cardiac arrest: a consensus statement from the European association for percutaneous cardiovascular interventions (EAPCI)/stent for life (SFL) groups. EuroIntervention. 2014;10:31-37. doi: 10.4244/EIJV10I1A7.

13. Ostenfeld S, Lindholm MG, Kjaergaard J, et al. Prognostic implication of out-of-hospital cardiac arrest in patients with cardiogenic shock and acute myocardial infarction. Resuscitation. 2015;87:57-62. doi: 10.1016/j. resuscitation.2014.11.010.

14. 2014 ESC/EACTS Guidelines on myocardial revascularization: The Task Force on Myocardial Revascularization of the European Society of Cardiology (ESC) and the European Association for Cardio-Thoracic Surgery (EACTS) Developed with the special contribution of the European Association of Percutaneous Cardiovascular Interventions (EAPCI). Eur Heart J. 2014;35:2541-2619. doi: 10.1093/eurheartj/ehu278.

15. Noc M, Fajadet J, Lassen JF, et al. Invasive Coronary Treatment Strategies for Out-Of-Hospital Cardiac Arrest: A Consensus Statement from the European Association for Percutaneous Cardiovascular Interventions (EAPCI)/Stent for Life (SFL) groups. EuroIntervention. 2014;10:31-37. doi: 10.4244/ EIJV10I1A7.

16. O'Gara PT, Kushner FG, Ascheim DD, et al. 2013 ACCF/AHA guideline for the management of ST-elevation myocardial infarction: a report of the American College of Cardiology Foundation/American Heart Association Task Force on Practice Guidelines. J Am Coll Cardiol. 2013;61:e78-e140. doi: 10.1016/j.jacc.2012.11.019.

17. Anyfantakis ZA, Baron G, Aubry P, et al. Acute coronary Angiographic findings in survivors of out-of-hospital cardiac arrest. Am Heart J. 2009;157:312-318. doi: 10.1016/j. ahj.2008.09.016.

18. Randhawa VK, Nagpal AD, Lavi S. Out-of-Hospital Cardiac Arrest and Acute Coronary Syndromes: Reviewing PostResuscitation Care Strategies. Can J Cardiol. 2015;31:14771480. doi: 10.1016/j.cjca.2015.05.001.

19. Waldo SW, Chang L, Strom JB, O'Brien C, Pomerantsev E, Yeh RW. Predicting the Presence of an Acute Coronary Lesion Among Patients Resuscitated From Cardiac Arrest. Circ Cardiovasc Interv. 2015;8. doi: 10.1161/CIRCINTERVENTIONS.114.002198.

20. Kern KB. Importance of invasive interventional strategies in resuscitated patients following sudden cardiac arrest. Interv Cardiol. 2011;3:649-661. doi:10.2217/ica.11.79.

21. Kern KB, Lotun $\mathrm{K}$, Patel $\mathrm{N}$, et al. Outcomes of Comatose Cardiac Arrest Survivors With and Without ST-Segment Elevation Myocardial Infarction: Importance of Coronary Angiography. JACC Cardiovasc Interv. 2015;8:1031-1040. doi: 10.1016/j.jcin.2015.02.021.

22. Nikolaou NI, Arntz HR, Bellou A, et al. European Resuscitation 
Council Guidelines for Resuscitation 2015 Section 8. Initial management of acute coronary syndromes. Resuscitation. 2015;95:264-277. doi: 10.1016/j.resuscitation.2015.07.030.

23. Kern KB. Optimal treatment of patients surviving out-ofhospital cardiac arrest. JACC Cardiovasc Interv. 2012;5:597605. doi: 10.1016/j.jcin.2012.01.017.

24. Dumas F, Cariou A, Manzo-Silberman S, et al. Immediate percutaneous coronary intervention is associated with better survival after out-of-hospital cardiac arrest: insights from the PROCAT (Parisian Region Out of hospital Cardiac ArresT) registry. Circ Cardiovasc Interv. 2010;3:200-207. doi: 10.1161/ CIRCINTERVENTIONS.109.913665.

25. Bangalore S, Hochman JS. A routine invasive strategy for out-of-hospital cardiac arrest survivors: are we there yet? Circ Cardiovasc Interv. 2010;3:197-199. doi: 10.1161/ CIRCINTERVENTIONS.110.957241.

26. Barcan A, Kovacs I, Blendea C, Orzan M, Chitu M. Factors Associated with In-hospital Mortality in Patients with Acute Coronary Syndrome. Journal of Cardiovascular Emergencies. 2015;1:68-74. doi: 10.1515/jce-2015-0010.

27. Monsieurs KG, Nolan JP, Bossaert LL, et al. European Resuscitation Council Guidelines for Resuscitation 2015: Section 1. Executive summary. Resuscitation. 2015;95:1-80. doi: 10.1016/j.resuscitation.2015.07.038.

28. Patel N, Patel NJ, Macon CJ, et al. Trends and Outcomes of Coronary Angiography and Percutaneous Coronary Intervention After Out-of-Hospital Cardiac Arrest Associated With Ventricular Fibrillation or Pulseless Ventricular Tachycardia. JAMA Cardiol. 2016;1:890-899. doi: 10.1001/ jamacardio.2016.2860.

29. Geri G, Dumas F, Bougouin W. Immediate Percutaneous Coronary Intervention Is Associated With Improved Short- and Long-Term Survival After Out-of-Hospital Cardiac Arrest. Circ Cardiovasc Interv. 2015;8. doi: 10.1161/ CIRCINTERVENTIONS.114.002303.

30. Geri G, Dumas F, Cariou A. Should we perform a coronary angiography in all cardiac arrest survivors? Curr Opin Crit Care. 2014;20:273-279. doi: 10.1097/MCC.0000000000000093.

31. Bro-Jeppesen J, Kjaergaard J, Wanscher M, et al. Emergency coronary angiography in comatose cardiac arrest patients: do real-life experiences support the guidelines? European Heart Journal Acute Cardiovascular Care. 2012;1:291-301. doi:10.1177/2048872612465588.

32. Kagawa E, Dote $K$, Kato $M$, et al. Should we emergently revascularize occluded coronaries for cardiac arrest?: rapid-response extracorporeal membrane oxygenation and intra-arrest percutaneous coronary intervention. Circulation. 2012;126:1605-1613. doi: 10.1161/ CIRCULATIONAHA.111.067538.

33. Kagawa E, Dote K, Kihara Y. Percutaneous coronary intervention for postcardiac arrest syndrome. Curr Opin Cardiol. 2013;28:689-694. doi: 10.1097/HCO.ob013e32836553b7.

34. Bedreag OH, Papurica M, Rogobete AF, Sandesc D. Influence of Hypothermia on the Clinical and Molecular Status of a Freshwater Drowning Victim with Severe Trauma. A Case Report. Journal of Interdisciplinary Medicine. 2015;1:186-188. doi: 10.1515/jim-2016-0029.

35. Kerans V, Espinoza A, Skulstad H, Halvorsen PS, Edvardsen T, Bugge JF. Systolic left ventricular function is preserved during therapeutic hypothermia, also during increases in heart rate with impaired diastolic filling. Intensive Care Med Exp. 2015;3:41. doi: 10.1186/s40635-015-0041-6.

36. Gunn AJ, Thoresen M. Hypothermic neuroprotection. NeuroRx. 2006;3:154-169. doi: 10.1016/j.nurx.2006.01.007.
37. Froehler MT, Geocadin RG. Hypothermia for neuroprotection after cardiac arrest: mechanisms, clinical trials and patient care. J Neurol Sci. 2007;261:118-126. doi: 10.1016/j. jns.2007.04.042.

38. Dumas F, Grimaldi D, Zuber B, et al. Is Hypothermia After Cardiac Arrest Effective in Both Shockable and Nonshockable Patients? Circulation. 2011;123:877-886. doi: 10.1161/ CIRCULATIONAHA.110.987347.

39. Chan PS, McNally B, Tang F, Kellermann A, CARES Surveillance Group.Recent Trends in Survival from Out-of-Hospital Cardiac Arrest in the United States. Circulation. 2014;130:1876-1882. doi: 10.1161/CIRCULATIONAHA.114.009711.

40. Testori C, Sterz F, Behringer W, et al. Mild therapeutic hypothermia is associated with favourable outcome in patients after cardiac arrest with non-shockable rhythms. Resuscitation. 2011;82:1162-1167. doi: 10.1016/j. resuscitation.2011.05.022.

41. Hollenberg J, Herlitz J, Lindqvist J, et al. Improved survival after out-of-hospital cardiac arrest is associated with an increase in proportion of emergency crew-witnessed cases and bystander cardiopulmonary resuscitation. Circulation. 2008;118:389-396. doi: 10.1161/CIRCULATIONAHA.107.734137.

42. Vaahersalo J, Hiltunen $P$, Tiainen $M$, et al. Therapeutic hypothermia after out-of-hospital cardiac arrest in Finnish intensive care units: the FINNRESUSCI study. Intensive Care Med. 2013;39:826-837. doi: 10.1007/s00134-013-2868-1.

43. Nielsen N, Wetterslev J, Cronberg T, et al. Targeted temperature management at $33 \mathrm{C}$ versus $36 \mathrm{C}$ after cardiac arrest. N Engl J Med. 2013;369:2197-2206. doi: 10.1056/NEJMoa1310519.

44. Ibrahim K, Christoph M, Schmeinck S, et al. High rates of prasugrel and ticagrelor non-responder in patients treated with therapeutic hypothermia after cardiac arrest. Resuscitation. 2014;85:649-656. doi: 10.1016/j.resuscitation.2014.02.004.

45. Donnino MW, Andersen LW, Berg KM, et al. Temperature Management After Cardiac Arrest An Advisory Statement by the Advanced Life Support Task Force of the International Liaison Committee on Resuscitation and the American Heart Association Emergency Cardiovascular Care Committee and the Council on Cardiopulmonary, Critical Care, Perioperative and Resuscitation. Resuscitation. 2016;98:97-104. doi: 10.1016/j.resuscitation.2015.09.396.

46. Penela D, Magaldi M, Fontanals J, et al. Hypothermia in acute coronary syndrome: brain salvage versus stent thrombosis? J Am Coll Cardiol 2013;61:686-687. doi: 10.1016/j. jacc.2012.10.029.

47. Nolan JP, Soar J, Cariou A, et al. European Resuscitation CouncilandEuropean Society of Intensive Care Medicine Guidelines for Post-resuscitation Care 2015 Section 5 of the European Resuscitation Council Guidelines for Resuscitation. Intensive Care Med. 2015;41:2039-2056. doi: 10.1007/s00134015-4051-3.

48. Rab T, Kern KB, Tamis-Holland JE, et al. Cardiac Arrest: A Treatment Algorithm for Emergent Invasive Cardiac Procedures in the Resuscitated Comatose Patient. J Am Coll Cardiol. 2015;66:62-73. doi: 10.1016/j.jacc.2015.05.009.

49. Mooney MR, Unger BT, Boland LL, et al. Therapeutic hypothermia after out-of-hospital cardiac arrest: evaluation of a regional system to increase access to cooling. Circulation. 2011;124:206-214. doi: 10.1161/CIRCULATIONAHA.110.986257.

50. Irisawa T, Vadeboncoeur TF, Karamooz M, et al. Duration of Coma in Out-of-Hospital Cardiac Arrest Survivors Treated With Targeted Temperature Management. Ann Emerg Med. 2017;69:36-43. doi: 10.1016/j.annemergmed.2016.04.021.

51. Maznyczka AM, Gershlick AH. Therapeutic hypothermia in 
patients with out-of-hospital arrest. Heart. 2015. doi:10.1136/ heartjnl-2014-307411.

52. Joffre J, Varenne O, Bougouin W, Rosencher J, Mira JP, Cariou A. Stent thrombosis: an increased adverse event after angioplasty following resuscitated cardiac arrest. Resuscitation. 2014;85:769-773. doi: 10.1016/j.resuscitation.2014.02.013.

53. Shah N, Rahul C, Kathan M, et al. Therapeutic Hypothermia and Stent Thrombosis: A Nationwide Analysis. JACC Cardiovasc Interv. 2016 Sep 12;9(17):1801-11. doi: 10.1016/j. jcin.2016.06.052.

54. Kang IS, Fumiaki I, Pyun WB. Therapeutic Hypothermia for Cardioprotection in Acute Myocardial Infarction. Yonsei Medical Journal. 2016;57:291-297. doi:10.3349/ ymj.2016.57.2.291.

55. Schenone AL, Cohen A, Patarroyo G. Therapeutic hypothermia after cardiac arrest: A systematic review/meta-analysis exploring the impact of expanded criteria and targeted temperature. Resuscitation. 2016;108:102-110. doi: 10.1016/j. resuscitation.2016.07.238.

56. Tissier R, Ghaleh B, Cohen MV, Downey JM, Berdeaux A. Myocardial protection with mild hypothermia. Cardiovasc Res. 2012;94:217-225. doi: 10.1093/cvr/cvr315.

57. Bernard S. Hypothermia after cardiac arrest: expanding the therapeutic scope. Crit Care Med. 2009;37(7Suppl):S227-S233. doi: 10.1097/CCM.ob013e3181aa5doc.

58. Grunau BE. Prehospital initiation of mild therapeutic hypothermia for out-of-hospital cardiac arrest (OHCA): where are we now? CJEM. 2015;17:227-230. doi: 10.1017/cem.2015.32.

59. Lyon R. Therapeutic hypothermia post out-of-hospital cardiac arrest - more questions than answers? Crit Care. 2011;15:151. doi: $10.1186 /$ cc10123.

6o. Benedek T, Marton-Popovici M, Glogar D. Extracorporeal Life Support and New Therapeutic Strategies for Cardiac Arrest Caused by Acute Myocardial Infarction - a Critical Approach for a Critical Condition. The Journal of Critical Care Medicine. 2016;1;2:164-174. doi: 10.1515/jccm-2016-0025.

61. Sharma AS, Pijls RWM, Weerwind PW, et al. Out-of-hospital cardiac arrest: the prospect of E-CPR in the Maastricht region. Netherlands Heart Journal. 2016;24:120-126. doi:10.1007/ s12471-015-0782-6.

62. Mosier JM, Kelsey M, Raz Y, et al. Extracorporeal membrane oxygenation (ECMO) for critically ill adults in the emergency department: history, current applications, and future directions. Critical Care. 2015;19:431. doi:10.1186/s13054-015-1155-7.

63. Ahn C, Kim W, Cho Y, Choi K-S, Jang B-H, Lim TH. Efficacy of extracorporeal cardiopulmonary resuscitation compared to conventional cardiopulmonary resuscitation for adult cardiac arrest patients: a systematic review and meta-analysis. Scientific Reports. 2016;6:34208. doi:10.1038/srep34208.

64. Stub D, Bernard S, Duffy SJ, Kaye DM. Post cardiac arrest syndrome: a review of therapeutic strategies Circulation. 2011;123:1428-1435. doi: 10.1161/ CIRCULATIONAHA.110.988725.

65. Pagani FD, Aaronson KD, Swaniker F, Bartlett RH. The use of extracorporeal life support in adult patients with primary cardiac failure as a bridge to implantable left ventricular assist device. Ann Thorac Surg. 2001;71(3Suppl):S77-S81.

66. Dalle Ave AL, Shaw DM, Gardiner D. Extracorporeal membrane oxygenation (ECMO) assisted cardiopulmonary resuscitation or uncontrolled donation after the circulatory determination of death following out-of-hospital refractory cardiac arrest-An ethical analysis of an unresolved clinical dilemma. Resuscitation. 2016;108:87-94. doi: 10.1016/j. resuscitation.2016.07.003.
67. Reynolds JC, Frisch A, Rittenberger JC, et al. Duration of resuscitation efforts and functional outcome after out-ofhospital cardiac arrest: when should we change to novel therapies? Circulation. 2013;128:2488-94. doi:10.1161/ CIRCULATIONAHA.113.002408.

68. Radsel P, Knafelj R, Kocjancic S, et al. Angiographic characteristics of coronary disease and postresuscitation electrocardiograms in patients with aborted cardiac arrest outside a hospital. Am J Cardiol. 2011;108:634-638. doi: 10.1016/j.amjcard.2011.04.008.

69. Benedek I, Gyongyosi M, Benedek T. A prospective regional registry of ST-elevation myocardial infarction in Central Romania: Impact of the Stent for Life Initiative recommendations on patient outcomes. Am Heart J. 2013;166:457-465. doi: 10.1016/j.ahj.2013.03.033.

70. Jacobs AK. Regional Systems of Care for Patients With STElevation Myocardial Infarction Circulation. 2007;116:689692. doi: 10.1161/CIRCULATIONAHA.107.720946

71. Nichol G, AufderheideTP, Eigel B, et al. Regional Systems of Care for Out-of-Hospital Cardiac Arrest. Circulation. 2010;121:709729. https://doi.org/10.1161/CIR.ob013e3181cdb7db.

72. McNally B, Robb R, Mehta M, et al. Centers for Disease Control and Prevention. Out-of-hospital cardiac arrest surveillanceCardiac Arrest Registry to Enhance Survival (CARES). MMWR Surveill Summ. 2011;60(SS08):1-19.

73. Hasselqvist-Ax I, Riva G, Herlitz J, et al. Early cardiopulmonary resuscitation in out-of-hospital cardiac arrest. N Engl J Med. 2015;372:2307-2315. doi: 10.1056/NEJMoa1405796.

74. Callaway CW, Donnino MW, Fink EL, et al. Part 8: Post-Cardiac Arrest Care: 2015 American Heart Association Guidelines Update for Cardiopulmonary Resuscitation and Emergency Cardiovascular Care. Circulation. 2015;132(18Suppl2):S465-S\$82. doi: 10.1161/ CIR.0000000000000262.

75. Azeli Y, Barbería E, Jiménez-Herrera $M$, et al. The ReCaPTa Study - a Prospective out of Hospital Cardiac Arrest Registry Including Multiple Sources of Surveillance for the Study of Sudden Cardiac Death in the Mediterranean Area. Scand J Trauma Resusc Emerg Med. 2016;24:127.doi: 10.1186/s13049016-0309-1.

76. Kajino K, Iwami T, Daya M, et al. Impact of transport to critical care medical centers on outcomes after out-of-hospital cardiac arrest. Resuscitation. 2010;81:549-554. doi: 10.1016/j. resuscitation.2010.02.008.

77. Hwang WS, Park JS, Kim SJ, Hong YS, Moon SW, Lee SW. A system-wide approach from the community to the hospital for improving neurologic outcomes in out-of-hospital cardiac arrest patients. Eur J Emerg Med. 2015. doi: 10.1097/ MEJ.0000000000000313.

78. Yamada T, Kitamura T, Hayakawa K, et al. Rationale, design, and profile of Comprehensive Registry of In-Hospital Intensive Care for OHCA Survival (CRITICAL) study in Osaka, Japan. Journal of Intensive Care. 2016;4:10. doi:10.1186/ s40560-016-0128-5.

79. Ringh M, Rosenqvist M, Hollenberg J, et al. Mobile-phone dispatch of laypersons for CPR in out-of-hospital cardiac arrest. N Engl J Med. 2015;372:2316-2325. doi: 10.1056/ NEJMoa1406038.

80. Kern KB. Usefulness of cardiac arrest centers - extending lifesaving post-resuscitation therapies: the Arizona experience. Circ J. 2015;79:1156-1163. doi: 10.1253/circj.CJ-15-0309.

81. Donnino MW, Rittenberger JC, Gaieski D, et al. The development and implementation of cardiac arrest centers. Resuscitation. 2011;82:974-978. doi:10.1016/j.resuscitation.2011.03.021. 